\title{
AUTISMATH: Aplicativo para Auxiliar o Ensino e Aprendizagem de Matemática para Crianças com Transtorno do Espectro Autista
}

\author{
Eduardo Felipe Martins da Cruz ${ }^{1}$, Rubenvaldo Monteiro Pereira² \\ ${ }^{1}$ Faculdade de Matemática (FAMAT) - Universidade Federal do Pará (UFPA) - \\ Cametá, PA - Brasil \\ ${ }^{2}$ Faculdade de Matemática (FAMAT) - Universidade Federal do Pará (UFPA) - \\ Cametá, PA - Brasil \\ eduardomartins5310@gmail.com, rubenvaldop@yahoo.com.br
}

\begin{abstract}
This article aims to present the "AUTISMATH" application prototype, developed with the aim of assist teaching and learning process of Mathematics content to autistic students in. The application, developed for mobile devices, was based on consolidated methods in the educational accompaniment of autistic people, based on Behaviorism. Among the preliminary results, there was a good acceptance of the application by professionals who work with these students and their contribution to the teaching and learning process.
\end{abstract}

Resumo. Este artigo tem como objetivo apresentar o protótipo de aplicativo "AUTISMATH", desenvolvido com o intuito de auxiliar no processo de ensino aprendizagem de educandos autistas em conteúdos de Matemática. $O$ aplicativo, desenvolvido para dispositivos móveis, foi fundamentado por métodos consolidados no acompanhamento educacional de autistas, baseados no Behaviorismo. Dentre os resultados preliminares, constatou-se a boa aceitação do aplicativo por profissionais que trabalham com esses educandos e sua contribuição no processo de ensino aprendizagem dos mesmos.

\section{Introdução}

A sociedade atual tem pautado constantemente a temática da inclusão em suas discussões. Em relação ao ambiente escolar, a discussão ganha ainda mais vigor. Contudo, promover a inclusão escolar de educandos com necessidades especiais é um tema desafiador devido à falta de recursos educacionais para atender esta demanda. Dentre os educandos com necessidades especiais mais comuns na comunidade escolar, crianças com autismo se destacam pelas peculiaridades deste transtorno. Adaptar metodologias e alternativas didáticas para educandos autistas através de softwares computacionais é uma das formas de promover a inclusão educacional desses educandos.

De acordo com Monte e Santos (2004), o Transtorno do Espectro Autista (TEA) afeta uma variedade de aspectos do desenvolvimento do indivíduo, e possui uma série de características, como hiperatividade, contato visual deficiente, problemas de comunicação, socialização, concentração e, em alguns casos, deficiência mental [Monte e Santos 2004]. Não há dados oficiais de quantos autistas existem no Brasil, porém, segundo a revista Espaço Aberto da Universidade de São Paulo (USP) há uma estimativa de que existam 2 milhões desses indivíduos no país, baseada em dados do Center of Deseases Control and Prevention (CDC), um órgão governamental dos Estados Unidos 
[Oliveira 2015]. Ao analisar esse dado, percebemos a importância de tornar o ambiente escolar mais inclusivo para os educandos autistas, visto o seu número expressivo e as dificuldades que encontram durante seu desenvolvimento.

Um dos grandes desafios encontrados por alunos da Educação Básica está relacionado à Matemática, e isso se evidencia ao analisar o desempenho dos estudantes em exames como o Programa Internacional de Avaliação de Alunos (PISA). Este exame avalia o desempenho de jovens nas áreas de ciências, português e Matemática e, em sua edição mais recente (2018), dois terços dos brasileiros de 15 anos mostraram saber menos que o básico em Matemática [Moreno 2019]. Em contraste com essa dificuldade há o papel fundamental da Matemática na vida do indivíduo, pois serve como base para outras disciplinas, bem como fornece conceitos práticos que podem ser utilizados em seu dia-adia. Os Parâmetros Curriculares Nacionais (PCN) dão ênfase a esses pontos quando dizem que:

é importante, que a Matemática desempenhe, equilibrada e indissociavelmente, seu papel na formação de capacidades intelectuais, na estruturação do pensamento, na agilização do raciocínio dedutivo do aluno, na sua aplicação a problemas, situações da vida cotidiana e atividades do mundo do trabalho e no apoio à construção de conhecimentos em outras áreas curriculares. [Brasil 1997, p. 29].

A dificuldade em aprender Matemática também é apresentada por educandos autistas, como enfatizado por Larkey e Adkins (2013), quando afirmam que há um mito em torno da ideia de que todo autista é bom em Matemática, pois assim como ler e escrever, a Matemática também lhe deve ser ensinada [Larkey e Adkins 2013].

A Base Nacional Comum Curricular (BNCC) afirma que "ao aproveitar o potencial de comunicação do universo digital, a escola pode instituir novos modos de promover a aprendizagem, a interação e o compartilhamento de significados entre professores e estudantes" [Brasil 2017, p. 61]. Um desses novos modos de promover a aprendizagem por meio desse universo digital é utilizando jogos para fins educacionais. Já Monteiro, Magagnin e Araújo (2009, p. 4) destacam que:

os jogos, de uma maneira geral, podem trazer muitas contribuições à formação do aluno, propiciando o desenvolvimento de diversas capacidades cognitivas, afetivas e sociais, além de momentos de lazer e descontração, podendo, portanto, fazer parte das diversas etapas da vida [Monteiro, Magagnin e Araújo 2009, p. 4].

Assim, este trabalho tem como objetivo apresentar uma proposta de software educacional em forma de jogo digital denominado "AUTISMATH", como auxiliar no processo de ensino aprendizagem de Matemática a educandos autistas.

Este artigo está organizado em 5 seções: na primeira seção apresentamos uma breve introdução. Na seção 2 tratamos do desenvolvimento do software, enquanto que na seção 3 apresentamos o AUTISMATH. Já na seção 4 tratamos dos resultados preliminares obtidos com a pesquisa de campo e, por fim, na seção 5 são feitas as considerações finais.

\section{Desenvolvimento do Software}

Para desenvolver o software foi necessário realizar um estudo acerca da forma como é realizado o acompanhamento educacional de autistas. O autismo é um transtorno que vem sendo estudado há décadas, e como fruto desses estudos desenvolveram-se métodos que 
tem como objetivo melhorar a qualidade de vida do indivíduo portador do TEA e promover seu desenvolvimento intelectual de forma a se aproximar ao máximo do que se espera em sua idade cronológica [Locatelli e Santos 2016]. A seguir, serão apresentados os métodos mais utilizados no acompanhamento educacional do autismo:

\begin{abstract}
ABA
ABA (do inglês Applied Behavior Analysis) é um método fundamentado nas bases da teoria comportamental do Behaviorismo, e tem como objetivo analisar o comportamento do indivíduo e modificá-lo com o uso de reforçadores. Esse método pode ser aplicado nos mais diversos casos, com educandos possuindo algum tipo de transtorno ou não. Quando utilizado no acompanhamento de educandos autistas, tem como objetivo desenvolver as potencialidades destes, no que diz respeito aos seus problemas de comunicação e interação social, bem como desenvolver habilidades motoras e demais obstáculos que o educando possa enfrentar ao longo de sua vida [Locatelli e Santos 2016].

O ABA trabalha com o educando autista, em um primeiro momento, atividades que produzam estímulos e gerem comportamentos. Em seguida faz a análise constante dessa relação (estímulo-comportamento), de modo a repetir os estímulos que gerem comportamentos pertinentes ao acompanhamento educacional, ou seja, que venham a contribuir com o desenvolvimento do educando, enquanto que estímulos que gerem comportamentos negativos tendem a ser evitados, de modo a se minimizar sua ocorrência [Camargo e Rispoli 2013]. Esse método é um dos mais utilizados atualmente no acompanhamento de educandos autistas por ser passível de controle parcial (na figura dos estímulos), e de reprodução. Aplicações do método que gerem bons resultados com determinado grupo de educandos autistas podem ser reproduzidas em outros grupos, de modo a analisar novamente o comportamento dos novos educandos a fim de realizar as alterações necessárias, visando bons resultados norteados pelo primeiro grupo [Camargo e Rispoli 2013].
\end{abstract}

\title{
TEACCH
}

O programa TEACCH (do inglês Treatment and Education of Autistic and related Communications Handicapped Children), tem como objetivo promover uma melhor qualidade de vida ao educando autista, bem como um melhor desenvolvimento de suas capacidades nas áreas de comunicação e interação social, como no método ABA. Porém esse programa também foca em pontos fortes que educandos autistas apresentam frequentemente, como seu processamento visual, seu apego às rotinas pré-estabelecidas e seus interesses específicos [Morais 2012].

O programa TEACCH está fundamentado na teoria comportamental do Behaviorismo e na psicolinguística, de modo a uma complementar a outra. Enquanto o Behaviorismo trabalha a valorização de descrições, condutas e dos programas passo a passo, a psicolinguística contribui com estratégias que buscam compensar os déficits comunicativos em educandos com TEA, por meio da utilização de recursos visuais [Kwee, Sampaio e Atherino 2009].

O TEACCH é flexível e adapta-se a cada pessoa, pois cada indivíduo possui suas particularidades. Vale ressaltar também que este programa se inicia na infância, mas pode acompanhar o educando autista ao longo de toda sua vida, desenvolvendo suas potencialidades, independência e participação ativa perante a sociedade, enquanto busca melhorar sua qualidade de vida [Locatelli e Santos 2016]. 
Na construção do software, além dos métodos utilizados no acompanhamento educacional de autistas, foi utilizado o livro Practical Mathematics for Children with an Autism Spectrum Disorder and Other Developmental Delays, escrito por duas professoras que trabalham com educandos autistas. O livro contém uma série de atividades que serviram como base para os jogos presentes no software, indo desde a identificação dos números, cores e formas à construção de sequências lógicas e numéricas.

O programa escolhido para dar vida ao software foi o Unity, devido à sua gratuidade e à multiplicidade de plataformas para as quais o jogo pode ser construído, dentre elas podemos citar o Windows, o Linux e o Android. Todas as artes do jogo, incluindo figuras, sons e músicas são de uso livre.

\section{Apresentação do Software}

O aplicativo AUTISMATH foi pensado visando alunos da Educação Infantil e anos iniciais do Ensino Fundamental, de modo a exercitar sua coordenação motora ao arrastar os objetos na tela do smartphone ou tablet, ou com o uso do mouse no computador. $\mathrm{O}$ aplicativo conta atualmente com 6 jogos independentes com a mesma mecânica, arrastar objetos até os locais solicitados.

A tela inicial do aplicativo solicita que o usuário selecione o jogo que deseja jogar, como pode ser observado na Figura 1.

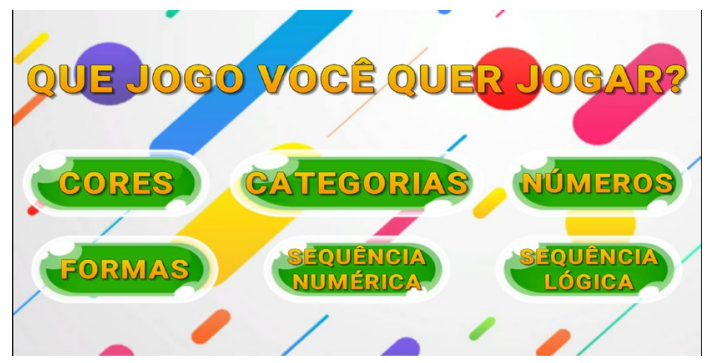

Figura 1. Tela inicial do aplicativo

Após selecionado o jogo, uma nova tela surge com as opções de jogar, as opções do jogo e o botão de voltar. Nas opções é possível silenciar o som e a música do jogo. Se o jogador apertar o botão "jogar", uma nova tela surge pedindo para selecionar o nível de dificuldade desejado, como pode ser observado na Figura 2. A cada novo nível, mais objetos são adicionados ao jogo, fazendo com que a identificação do objeto correto seja dificultada.

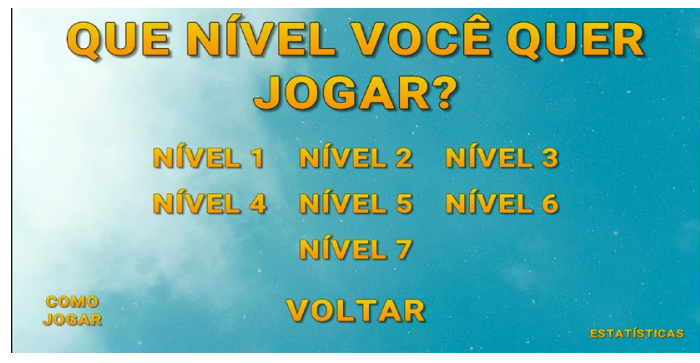

Figura 2. Tela de seleção de nível

Também podem ser observados os botões "como jogar" que ensina a jogar cada um dos jogos, e o botão "estatísticas" que mostra a quantidade de acertos, erros e partidas 
jogadas por nível de dificuldade. Dessa forma é possível monitorar o desenvolvimento do educando ao longo do acompanhamento.

Por fim, após selecionar o nível de dificuldade, o educando é apresentado ao jogo. São 6 jogos no total: Cores, Formas, Números, Categorias, Sequência Numérica e Sequência Lógica. Como exemplo, será utilizado o jogo dos números, como pode ser observado na Figura 3.

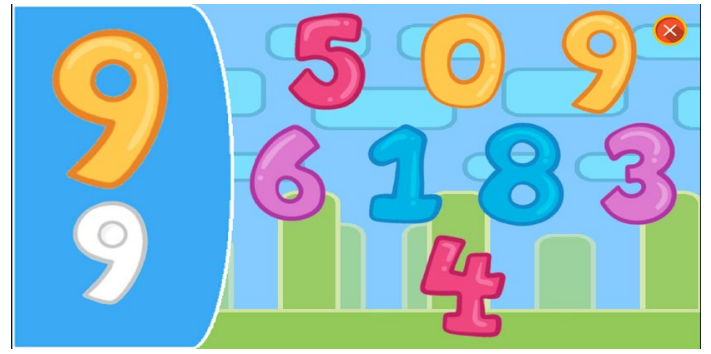

Figura 3. Exemplo de tela do jogo

Neste jogo o educando deve arrastar o número que está sendo solicitado no canto superior esquerdo até sua silhueta no canto inferior esquerdo. Ao clicar em um número que não está sendo solicitado, um efeito sonoro de erro pode ser ouvido e o número incorreto volta ao seu lugar inicial. Ao clicar e arrastar o número correto ao local indicado, uma tela de congratulações aparece, como pode ser observado na Figura 4. Nela, também é possível progredir para o próximo nível, regredir para o anterior, repetir o mesmo nível, trocar de jogo, ou ir para a tela de seleção de nível.

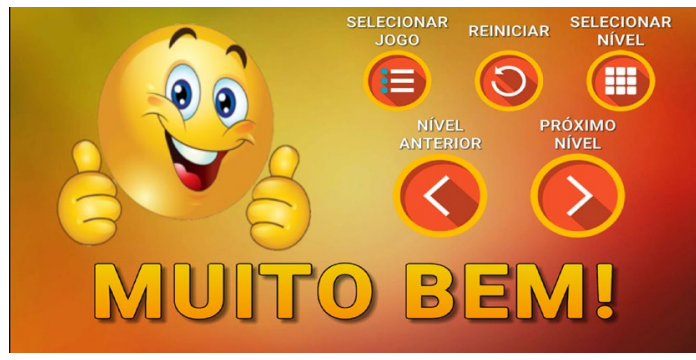

Figura 4. Tela de congratulações

O apelo visual, a progressão de dificuldade, os reforçadores positivos (tela de congratulações) e negativos (efeito sonoro de erro) presentes em todos os jogos do software são contribuições do Programa TEACCH e do método ABA, ambos fundamentados na teoria comportamental do Behaviorismo. Para os behavioristas, o ensino aprendizagem pode ser observado por meio de uma mudança no comportamento passível de observação, e as estatísticas do jogo cumprem esse papel, fornecendo dados que podem ser utilizados pelo educador para acompanhar a evolução do educando autista [Orrú 2008].

\section{Resultados Preliminares}

O protótipo do aplicativo foi disponibilizado a um grupo composto por quatro professoras que trabalham com educandos autistas e, junto a ele foi disponibilizado um questionário de avaliação do aplicativo, que contava com perguntas relacionadas às suas funcionalidades, importância no processo de ensino aprendizagem de educandos autistas e à importância dos dados estatísticos coletados do educando para esse processo. 
Todas as perguntas possuíam múltipla escolha, onde cada opção correspondia a um nível de satisfação relativo a determinado aspecto do aplicativo. As classificações foram divididas em: Muito ruim: $\mathrm{O}$ aspecto deve ser totalmente modificado; Ruim: $\mathrm{O}$ aspecto deve ser modificado bastante; Regular: $\mathrm{O}$ aspecto é satisfatório, mas pode ser melhorado; Ótimo: $\mathrm{O}$ aspecto correspondeu às expectativas e Excelente: $\mathrm{O}$ aspecto superou as expectativas.

O grupo mostrou um alto nível de satisfação com o aplicativo, avaliando de forma unânime o nível de confiança deste como auxiliar no processo de ensino aprendizagem de educandos autistas como "Ótimo". Com relação ao valor do aplicativo para o ensino aprendizagem desses educandos, as avaliações dividiram-se igualmente entre "Ótimo" e "Excelente", mostrando a eficácia do aplicativo como auxiliar no ensino aprendizagem de educandos autistas. Outro dado importante está relacionado à forma como as estatísticas do educando são registradas e sua importância, que tiveram avaliação de $75 \%$ Ótimo e $25 \%$ Excelente, ambas.

Os resultados preliminares são promissores, pois mostram uma boa aceitação do aplicativo por educadoras que trabalham a anos com educandos autistas no que fora inicialmente proposto, servir como ferramenta auxiliar no processo de ensino aprendizagem desses educandos em conteúdos de Matemática.

\section{Considerações Finais}

Educandos com os mais diversos tipos de problemas de desenvolvimento estão inseridos em nossos sistemas de ensino. E com a questão da inclusão ganhando cada vez mais força, não podemos fechar os olhos perante suas dificuldades.

Para efetivar a inclusão desses indivíduos, métodos de ensino alternativos e adaptados devem ser desenvolvidos para uso em sala de aula. Neste contexto, o universo digital mostra-se uma alternativa promissora, visto o número crescente de aparelhos eletrônicos no Brasil, chegando a mais de dois smartphones por habitante no país [Meirelles 2018].

Utilizar e adaptar jogos digitais para fins educacionais depende da capacidade do educador em perceber aspectos do jogo que possam ajudar a trabalhar determinado conceito, e dos recursos à sua disposição para pôr esse método em prática.

O software AUTISMATH está em constante desenvolvimento, buscando refinarse ainda mais como ferramenta auxiliar no ensino aprendizagem de educandos autistas, de modo a tornar o ensino desses educandos mais inclusivo, proveitoso e prazeroso.

Esta é uma pesquisa em desenvolvimento, porém, com grande potencial, devido à sua aceitação desde o primeiro momento e seus resultados preliminares satisfatórios. As próximas etapas da pesquisa abrangem a aplicação de outro questionário, com a finalidade de coletar dados acerca de como o aplicativo pode ser melhorado aos olhos das profissionais mencionadas anteriormente, em seguida, novos testes devem ser realizados, buscando o refinamento do protótipo.

Esperamos que o aplicativo contribua efetivamente para o ensino de educandos autistas, visto o número limitado de opções com esta proposta disponíveis no mercado atual e, sirva de inspiração para novos professores e desenvolvedores que buscam formas de contribuir para o ensino de educandos com necessidades especiais, bem como da comunidade escolar em geral. 


\section{Referências}

Brasil (2017) “Base Nacional Comum Curricular”. Brasília: MEC. Disponível em: $<$ http://basenacionalcomum.mec.gov.br/templates/bncc/images/pdf $>$. Acesso em: 30 jan. 2020.

Brasil (1997) "Parâmetros Curriculares Nacionais: Matemática”. Brasília: MEC/SEF.

Camargo, S. P. H., Rispoli, M. (2013) “Análise do comportamento aplicada como intervenção para o autismo: definição, características e pressupostos filosóficos". Revista Educação Especial, v. 26, n. 47, p. 639-650.

Larkey, S., Adkins, J. (2013) "Practical mathematics for children with an autism spectrum disorder and other developmental delays". Jessica Kingsley Publishers.

Locatelli, P. B., Santos, M. F. R. (2016) “Autismo: propostas de intervenção”. Revista Transformar, v. 8, n. 8, p. 203-220.

Meirelles, F. S. (2018) "Pesquisa anual do uso de TI nas empresas". FGV-EAESP. 29a edição.

Monte, F. F., Santos, I. B. (2004) "Saberes e práticas da inclusão, dificuldades acentuadas de aprendizagem: autismo". Brasília: MEC, SEESP.

Monteiro, T.V.B., Magagnin, C.D.M., Araújo, C.H.S (2009) “A importância dos jogos eletrônicos na formação do aluno". In: Anais do Simpósio de Estudos e Pesquisas da Faculdade de Educação. Universidade Federal de Goiás (UFG). Goiânia - GO, pp. $\mathrm{s} / \mathrm{n}$

Morais, T. L. C. (2012) "Modelo TEACCH: intervenção pedagógica em crianças com perturbações do espetro do autismo". Dissertação de Mestrado.

Moreno, A. (2019) "Pisa 2018: dois terços dos brasileiros de 15 anos sabem menos que o básico de matemática". Disponível em:

$<$ https://g1.globo.com/educacao/noticia/2019/12/03/pisa-2018-dois-tercos-dosbrasileiros-de-15-anos-sabem-menos-que-o-basico-de-matematica.ghtml $>$. Acesso em: 30 jan. 2020.

Oliveira, C. (2015) "Um retrato do autismo no Brasil". Revista Espaço Aberto.

Disponível em: $<$ http://www.usp.br/espacoaberto/?materia=um-retrato-do-autismono-brasil>. Acesso em: 30 jan. 2020.

Orrú, S. E. (2008) "Os estudos da análise do comportamento e a abordagem históricocultural no trabalho educacional com autistas". Revista Iberoamericana de Educación, v. 45, n. 3, p. 1. 